\title{
Thermal behavior of crystalline thin film silicon solar cells
}

\author{
Balázs Plesz, Gusztáv Hantos
}

Budapest University of Technology and Economics (BME), Dept. of Electron Devices, Budapest, Hungary

Email address:

plesz@eet.bme.hu.com(B. Plesz), hantos@eet.bme.hu(G. Hantos)

\section{To cite this article:}

Balázs Plesz, Gusztáv Hantos, Thermal Behavior of Crystalline Thin Film Silicon Solar Cell. International Journal of Renewable and Sustainable Energy, Vol. 2, No. 3, 2013, pp. 115-119. doi: 10.11648/j.ijrse.20130203.16

\begin{abstract}
The goal of this paper is to investigate the thermal behavior of crystalline thin film silicon solar cells, and to determine whether the decrease in cell thickness affects the temperature dependences of the solar cell parameters. For the investigation crystalline solar cells with a photoactive layer thickness of 26, 38 and 50 microns were processed. Sample cells were formed on $\mathrm{n}+$-substrate wafers with $\mathrm{n}$ epitaxial layers where due to the low minority carrier lifetime in the substrate only the epitaxial layer participates effectively in the photocurrent generation. The thin photoactive layers were achieved by the etching of the epitaxial layer. On the samples I-V curves and spectral response functions were measured at different temperatures, and the temperature coefficients of the short circuit current, the open circuit voltage and the efficiency were determined. Most of the parameters showed no differences in their temperature behavior, but the temperature dependence of the short circuit current differed on all three sample cells and was in correspondence with the changes of the temperature dependences of the spectral responses. From the results it can be concluded, that decreasing the thickness of the solar cells will have practically no effect on the temperature dependence of the performance and the efficiency of crystalline silicon solar cells. However the dependence of in the temperature coefficients for the short circuit currents on the thickness of the photoactive layer currents could be of interest for sensor applications, e.g. for the thermal compensation of light sensors.
\end{abstract}

Keywords: Solar Cells, Thermal Behavior, Thin Crystalline Solar Cells, I-V Curve, Spectral Response

\section{Introduction}

To enable photovoltaics to be competitive with other renewable or even conventional energy sources the costs for PV-systems have to be reduced. Since in case of conventional crystalline silicon solar cells more than $40 \%$ [1] of the manufacturing costs of a solar module are amounted only by the raw material, i. e. the silicon wafer, one of the leading goals in silicon solar cell development is to reduce the costs for the raw material. This can be reached by either reducing the costs of the feedstock or by decreasing silicon consumption. Latter one has found increasing interest recently $[2,3,4]$ and wafer thicknesses down to $20 \mu \mathrm{m}$ or even less by using direct film transfer [5] have been reported. This paper addresses the effects of thin wafer thicknesses on the thermal behaviour of the solar cell.

It is well known that solar cells change their current, voltage and generated power according to their operating temperature $[6,7,8,9,10]$, so the thermal behavior and the variation of the above mentioned parameters with changing temperatures is a crucial questions of solar cell operation. In previous research [11] we found that the thickness of the solar cell affects the thermal behavior, thus this correlation was taken under further investigation. For this purpose a method for preparing samples differing only in the thickness of the photoactive base layer was developed. The samples processed with this method were investigated by the means of $\mathrm{I}-\mathrm{V}$ characteristics and spectral response measurements at different temperatures.

\section{Experimental}

To simulate thin solar cell structures heavily doped $n+$ wafers with weakly doped n-type epitaxial layers were used Due to the very low minority carrier lifetime in the $n+$ substrate the charge carriers generated by the light that is absorbed in the $n+$ layer do not add to the current of the solar cell, so the structure can be approximately regarded as a solar cell with the thickness of the epitaxial layer only. This sample preparation method is based on the epitaxial wafer equivalent (EpiWE) approach [12].

The advantage of this method is that for the simulation of the electro-thermal behavior of thin crystalline silicon cells it is not necessary to perform the complicated processing of the thin wafers. In addition the mechanical stability is 
higher than in case of thin wafers, thus the handling during cell processing is easier and can be performed with methods and technologies used with normal wafers. With these the developed method is optimal for small laboratories that do not have newest, cost intensive processing and handling equipment available.

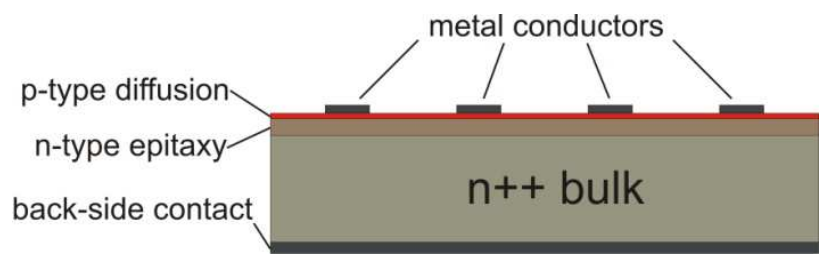

Figure 1. Cross-section of the sample cells. The different solar cell thicknesses are formed by etching the n-type epitaxial layer

Furthermore a BSF (back surface field) is generated at the $n+-n$ junction resulting in a decrease of minority carrier recombination at the back surface. The different layer thicknesses were reached by etching the n-type epitaxial layer in tetra-methyl-ammonium-hydroxide. The initial thickness of the epitaxial layer was measured as $60 \mu \mathrm{m}$, by etching the epitaxial layer three different thicknesses of 50, 38 and $26 \mu \mathrm{m}$ were formed (table 1). All sample cells were fabricated on the same wafer to eliminate all possible inequalities in the raw material and the fabrication process. To achieve this, the surface of the wafer was masked by thermally grown oxide, and the windows for the etching were opened with time delays, thus enabling a different etch time and a different thickness in each window. The backside was also masked by thermal oxide, to prevent unintentional doping at the diffusion steps during $p-n$ junction forming. The $\mathrm{p}-\mathrm{n}$ junction was formed by boron diffusion, and the front and back contacts are made up of evaporated aluminum (Fig. 1). Finally the wafer with the cells was diced and samples with an area of $13 \times 13 \mathrm{~mm}^{2}$ were formed.

\section{Measurements}

First the thickness of the completed cells was determined by a mechanical thickness gauge. The thickness of the $n+$ substrate $(350 \mu \mathrm{m})$ was determined by spreading resistance measurement, and was subtracted from the cell thickness resulting in the thickness of the photoactive layer (Table 1).

The I-V characteristics of the sample cells were investigated under a halogen lamp producing a light intensity of approximately $1000 \mathrm{~W} / \mathrm{m} 2$ at the front surface of the solar cells. The temperature of the cells was changed in the range of $5^{\circ} \mathrm{C}$ and $85^{\circ} \mathrm{C}$ in steps of $5^{\circ} \mathrm{C}$ with a thermostated cold plate. An I-V curve was obtained at every temperature step. The spectral response, i.e. the short circuit current as a function of the wavelength was measured at 8 different wavelengths: $392,465,550,622,5705,790,871,5$ and $1023 \mathrm{~nm}$. Similarly to the measurement of the I-V characteristics the temperature of the cells was altered in the range of $5^{\circ} \mathrm{C}$ and $75^{\circ} \mathrm{C}$ in steps of $10^{\circ} \mathrm{C}$ with a thermostated cold plate, where a spectral response was measured at every temperature step.

Table 1. Temperature coefficient of the sample cells

\begin{tabular}{|c|c|c|}
\hline Column1 & Cell B & Cell C \\
\hline thickne & 388 & 400 \\
\hline $\begin{array}{l}\text { Epitaxial layer (photoactive layer) thickness }{ }_{26} \\
{[\mu \mathrm{m}]}\end{array}$ & 38 & 50 \\
\hline $\begin{array}{l}\text { Temperature coefficient for optimal load }-0.1521 \\
{\left[\Omega /{ }^{\circ} \mathrm{C}\right]}\end{array}$ & -0.1783 & -0.1691 \\
\hline $\begin{array}{l}\text { Temperature coefficient for open circuit } 2.66 \\
\text { oltage }\left[\mathrm{V} /{ }^{\circ} \mathrm{C}\right]\end{array}$ & 2.66 & 2.64 \\
\hline
\end{tabular}

\section{Results and Evaluation}

From the I-V curves measured at different temperatures the following parameters were extracted: short circuit current, open circuit voltage, fill factor and optimal load. The temperature dependences for the different cells can be seen in Fig. 2-6. Note that the cells only differ in the thickness of the epitaxial layer, i.e. the thickness of the photoactive layer. The temperature coefficients derived from the temperature curves can be found in Table 1. The temperature dependence of the short circuit current could not be approximated with a linear fit (Fig. 5). After trying different functions the best results were obtained by using exponentials functions with negative linear coefficients and negative exponents. The fitted functions are described by the following equation:

$$
-a \cdot e^{-b x}+c
$$

The values of the fit parameters $a, b$ and $c$ are summarized in table 2. Since the fit is not linear, the temperature dependence of the short circuit current is not a constant, but a function of temperature. The increase of the short circuit current per temperature unit can be given as the first derivative of (1):

$$
a b \cdot e^{-b x}
$$

These temperature dependences of the short circuit currents are shown in Fig. 6.

Table 2. Fit parameter coefficients of the sample cells

\begin{tabular}{cccc}
\hline Parameter & Cell A & Cell B & Cell C \\
\hline a & 3.698 & 2.455 & 5.125 \\
b & 0.01476 & 0.01523 & 0.009714 \\
c & 21.58 & 17.55 & 21.57 \\
\hline
\end{tabular}

\section{Discussion}

Since the open circuit voltage is mainly influenced by the parameters of the $p-n$ junction, the temperature coefficient of the open circuit voltage shows practically no dependence on the thickness of the epitaxial layer. This also indicates that the $p-n$ junctions of the sample cells are mostly identical, thus eliminating effects that could be caused by differences 
in the parameters of the p-n junction, so every difference seen in the thermal behavior must be related to the differences in the photoactive layer thickness. As it can be seen from Table 1 the temperature coefficient of the (open circuit) voltage is by an order of magnitude higher than the temperature dependence of the (short circuit) current indicated in Fig. 6. Due to this the temperature dependence of the generated power is mainly influenced by the voltage and shows no significant changes for different values of the epitaxial layer thickness. However, the temperature coefficient of the short circuit current shows a variation with increasing thickness of the photoactive layer (fig 6).

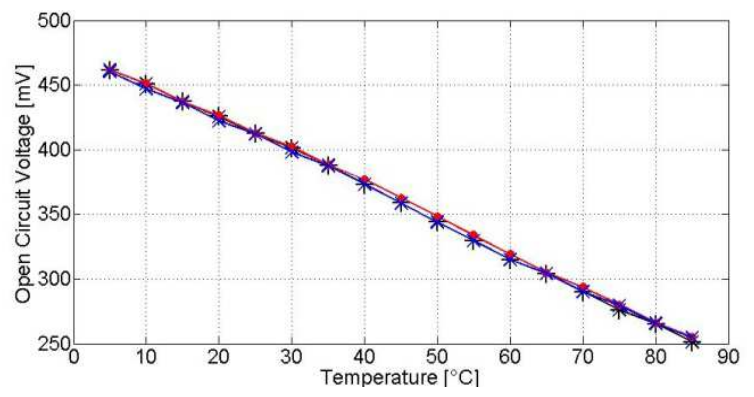

Figure 2. Open circuit voltages of the sample cells. Cells A, B, and C are marked with red dots, blue $X$-s and black stars respectively

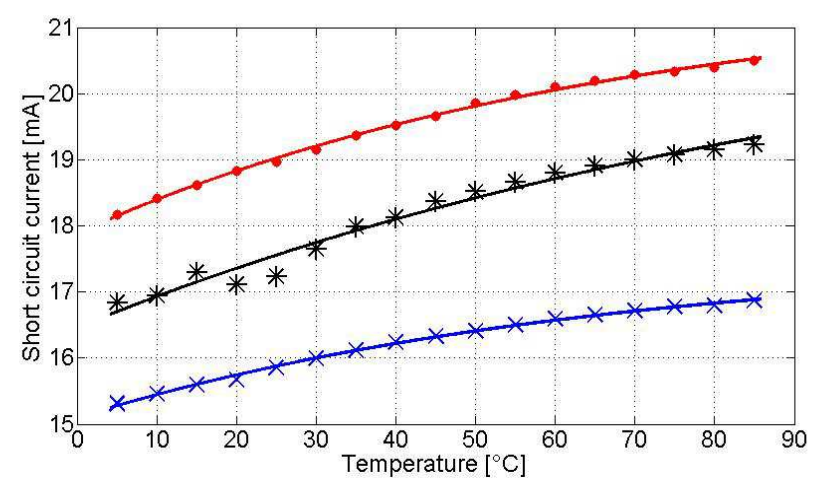

Figure 3. Short circuit currents of the cells. Cells A, B, and C are marked with red dots, blue $X$-s and black stars respectively, the solid lines represent an exponential fit to the respective datasets.

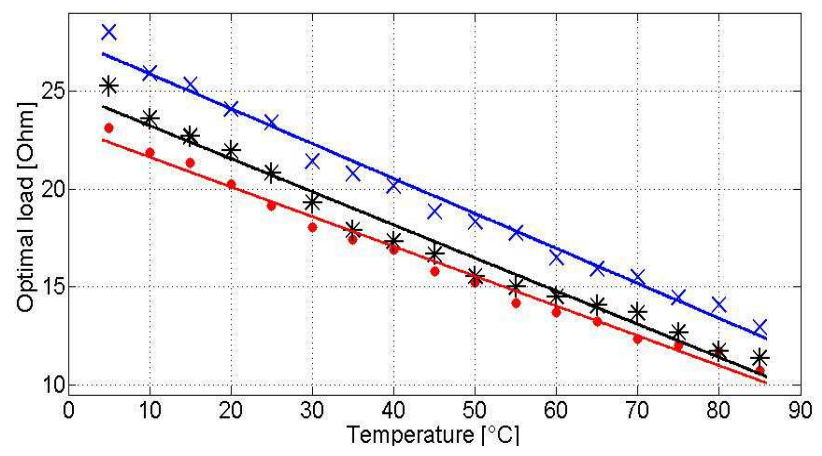

Figure 4. Optimal load of the sample cells. Cells A, B, and C are marked red dots, blue $X$-s and black stars respectively, the solid lines represent linear fits to each dataset.

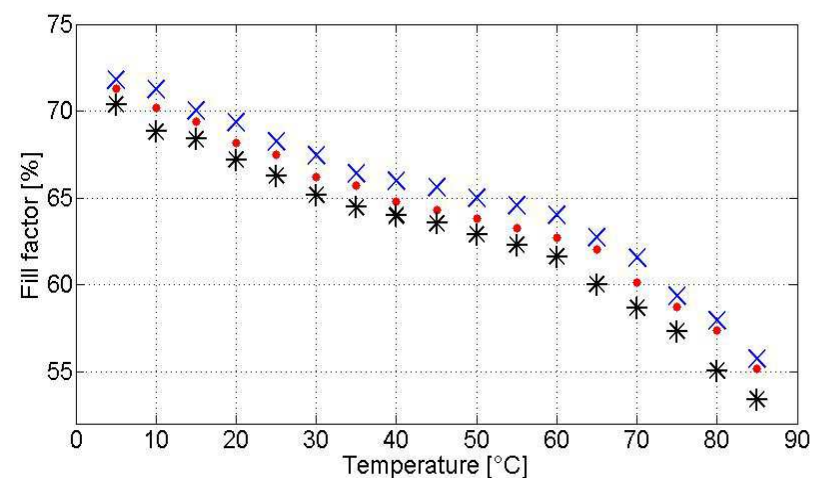

Figure 5. Fill factor of the sample cells. Cells A, B, and $C$ are marked with red dots, blue $X$-s and black stars respectively

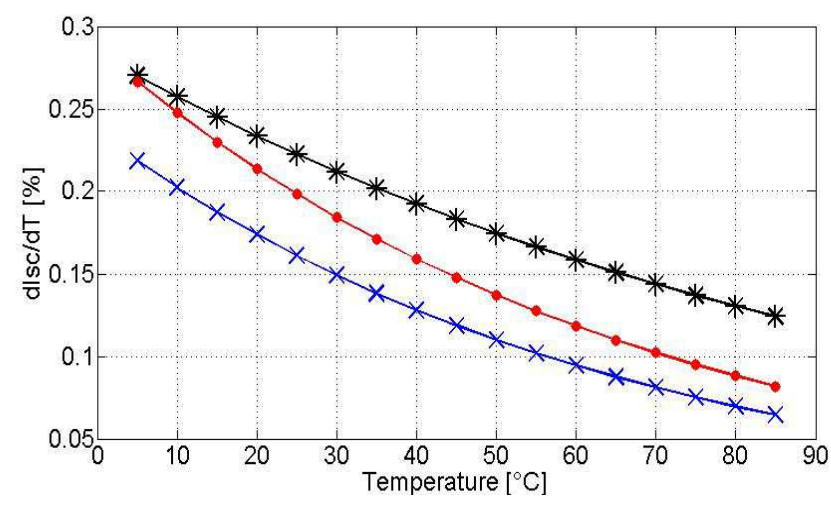

Figure 6. Temperature dependences of the short circuit current. Cells A, B, and $C$ are marked with red dots, blue $X$-s and black stars respectively. The figure shows curves calculated from (2)

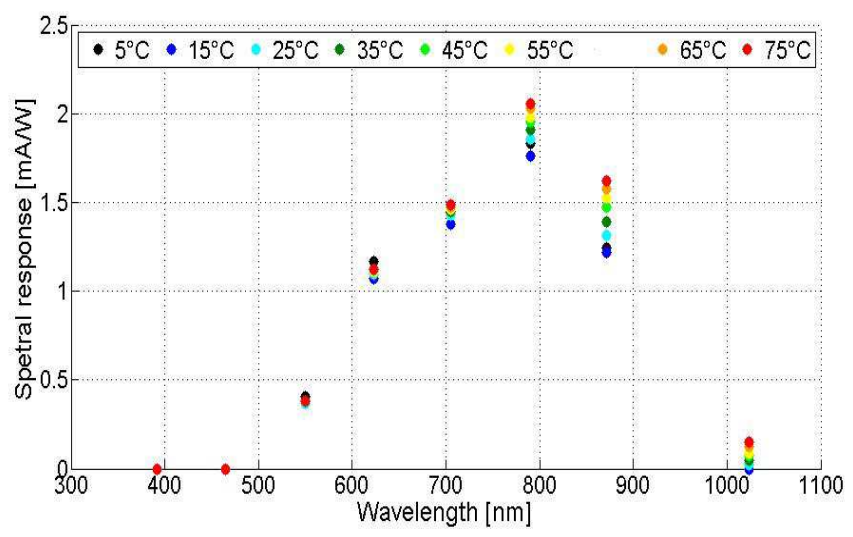

Figure 7. Spectral responses of cell B. Note the current increase in the near-IR region

On the spectral responses of the sample cells (in Fig. 7 cell $\mathrm{B}$ is shown) it can be seen that the currents generated by the red and near-IR components show a higher temperature dependence, than the components with lower wavelength, e. g. the components that are absorbed totally. The low spectral response in the low wavelength region is due to the lack of surface passivation of the solar cell and the low illumination intensity of the used equipment in the lower spectral region.

In Fig. 8 the temperature dependence of cell B is shown at the different investigated wavelengths. A linear fit was cal- 
culated at each investigated wavelength resulting in a linear thermal coefficient $\left(\% /{ }^{\circ} \mathrm{C}\right)$ for each investigated spectral component. These thermal coefficients are summarized in table 3. Fits were not performed for the wavelengths of 392 and $465 \mathrm{~nm}$, since the measurements results were to low to be evaluated at these two wavelengths.

It can be seen that with increasing wavelength the thermal coefficient rises. This indicates that the thermal behavior of the short circuit current is influenced mostly by the light components in the near IR-region. Comparing the thermal coefficients received for the spectral response at different wavelengths (table 3) the same dependence on thickness can be found as in case of the thermal dependence of the short circuit current.

Table 3. Fit parameter coefficients of the sample cells

\begin{tabular}{cccc}
\hline Wavelength $[\mathbf{n m}]$ & $\begin{array}{c}\text { temperature } \\
\text { coefficient } \\
\text { Cell A } \\
{\left[\%{ }^{\circ} \mathbf{C}\right]}\end{array}$ & $\begin{array}{c}\text { temperature } \\
\text { coefficient } \\
\mathbf{C e l l ~ B} \\
{\left[\%^{\circ} \mathbf{C}\right]}\end{array}$ & $\begin{array}{c}\text { temperature } \\
\text { coefficient } \\
\text { Cell C } \\
{\left[\% /{ }^{\circ} \mathbf{C}\right]}\end{array}$ \\
\hline 550 & 0,0569 & 0,0574 & $-0,15$ \\
622,5 & 0,0978 & 0,0639 & 0,18 \\
705 & 0,25 & 0,11 & 0,21 \\
790 & 0,3 & 0,25 & 0,36 \\
871,5 & 0,59 & 0,51 & 0,66 \\
1023 & 13,21 & 10,16 & 6,16 \\
\hline
\end{tabular}

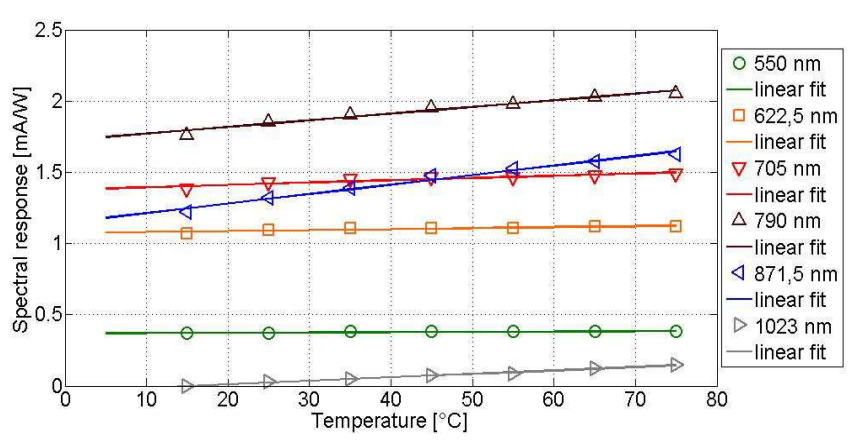

Figure 8. Temperature dependence of the spectral components. The solid lines represent a linear fit to the respective datasets. Note the increasing slope at higher wavelengths

A possible explanation for the thickness dependent temperature behavior of the short circuit current can be given as follows: The absorption factor of silicon rises with temperature. At a higher temperature a higher fraction of the incompletely absorbed light components is absorbed, thus generating higher currents. A thicker solar cell already absorbs a higher fraction of the light, thus the temperature induced additional absorption is lower than in case of thinner solar cells, as this can be seen in the case of sample A and B. This explanation is sufficient only if the photoactive layer is thinner than the diffusion length of the minority carriers. If the thickness of the photoactive layer is higher than the diffusion length the temperature dependence of the diffusion length has to be taken into account. Since the diffusion length increases with temperature, the temperature dependence of the open circuit voltage is additionally increased by the expansion of the collection zone of the charge carriers. In case of our samples the diffusion length is approx. $40 \mu \mathrm{m}$. Thus in case of sample $\mathrm{C}$ the thickness of the epitaxial layer is higher than the diffusion length which explains the higher temperature coefficients for the currents of sample $\mathrm{C}$. Another indication that in sample $\mathrm{C}$ the cell thickness exceeded the diffusion length is the decrease in short circuit current, since out of the range of the diffusion length the collection efficiency of the minority carriers decreases rapidly.

\section{Conclusions}

As to summarize it can be stated, that the thickness of a solar cell influences the temperature dependences of a solar cell, as it can be seen from the temperature dependence of the short circuit current. However, the temperature coefficient of the open circuit voltage is by an order of magnitude higher, thus it dominates the temperature dependence of the solar cell efficiency and performance. Since the temperature dependence of the voltage is rather determined by the parameters of the $p-n$ junction the temperature dependence of the generated power should be practically not influenced by changes in the thickness of the solar cell. However, the variation of the temperature dependence of the short circuit current with increasing photoactive layer thickness can be from interest where the short circuit current is of importance, for example in light sensing applications. The different thermal coefficients for the different spectral components, and their dependence on the photoactive layer thickness could also be from interest in applications, where only parts of the total solar spectrum are of importance.

\section{Acknowledgement}

This work is connected to the scientific program of the "Development of quality-oriented and harmonized $\mathrm{R}+\mathrm{D}+\mathrm{I}$ strategy and functional model at BME" project. This project is supported by the New Széchenyi Plan (Project ID: TÁMOP-4.2.1/B-09/1/KMR-2010-0002). The research was partially funded by the project TECH-08-D/2-2008-0101 of the National Development Agency and project No. K100794 of the Hungarian Scientific Research Fund (OTKA).

\section{References}

[1] R. G. Little and M. J. Nowlan: Crystalline silicon photovoltaics: the hurdle for thin films. Progress in Photovoltaics: Research and Applications, 5: 309-315, 1997

[2] P. Rosenits, F. Kopp, S. Reber, Epitaxially grown crystalline silicon thin-film solar cells reaching $16.5 \%$ efficiency with basic cell process, Thin Solid Films, Volume 519, Issue 10, Pages 3288-3290, 2011 
[3] G. P. Willeke, Thin crystalline silicon solar cells, Solar Energy Materials and Solar Cells, Volume 72, Issues 1-4, Pages 191-200, 2002

[4] Juris P. Kalejs, Silicon ribbons and foils--state of the art, Solar Energy Materials and Solar Cells, Volume 72, Issues 1-4, Pages 139-153, 2002

[5] F. Henley, A. Lamm, S. Kang, Z. Liu, L. Tian: Direct Film Transfer (DFT) Technology for Kerf-Free Silicon Wafering, Proceddings of 23rd European Photovoltaic Solar Energy Conference and Exhibition, 1-5 September 2008, Valencia, Spain, pp. 1090-1093

[6] M. A. Green: General temperature dependence of solar cell performance and implications for device modelling. Prog. Photovolt: Res. Appl., 11: 333-340, 2003

[7] John C.C. Fan, Theoretical temperature dependence of solar cell parameters, Solar Cells, Volume 17, Issues 2-3, Pages 309-315, 1986

[8] Rodolphe Vaillon, Lucile Robin, Cristian Muresan, Christophe Ménézo, Modeling of coupled spectral radiation, thermal and carrier transport in a silicon photovoltaic cell, International Journal of Heat and Mass Transfer, Volume 49, Issues 23-24, Pages 4454-4468, 2006

[9] E. Skoplaki, J.A. Palyvos, On the temperature dependence of photovoltaic module electrical performance: A review of efficiency/power correlations, Solar Energy, Volume 83, Issue 5, Pages 614-624, 2009

[10] E. Radziemska: Effect of temperature on dark current characteristics of silicon solar cells and diodes. Int. J. Energy Res., 30: 127-134., 2006

[11] B. Plesz, A. Foldvary, E. Bandy, Low cost solar irradiation sensor and its thermal behaviour, Microelectronics Journal, Volume 42, Issue 4, Thermal investigations of integrated circuits and systems, THERMINIC' 09, Pages 594-600, 2011

[12] Schmich, E., Lautenschlager, H., Frieß, T., Trenkle, F., Schillinger, N. and Reber, S., n-Type emitter epitaxy for crystalline silicon thin-film solar cells. Prog. Photovolt: Res. Appl., 16: 159-170, 2008 